\title{
Coronary surgery for unstable angina pectoris Incidence and mortality of perioperative myocardial infarction
}

\author{
RENE A. LANGOU, JOHN C. WILES, AND LAWRENCE S. COHEN \\ From the Department of Internal Medicine, Cardiology Section, Yale University School of Medicine, \\ New Haven, Connecticut, USA
}

SUMMARY The incidence of perioperative myocardial infarction determined by electrocardiogram was examined in 123 consecutive patients having only coronary artery bypass grafting for unstable angina pectoris, at Yale-New Haven Hospital from January 1974 to June 1975. The incidence of myocardial infarction and its mortality were correlated with clinical, haemodynamic, anatomical, and operative factors.

Myocardial infarction occurred in 18 per cent of all patients (22/123); 15 inferior, 6 anterior, and 1 anterolateral wall. Three factors appeared to be related to the occurrence of myocardial infarction: left main coronary artery disease (LMCD), $(47 \%, 7 / 15)$, increased left ventricular end-diastolic pressure (LVEDP), $(27 \%, 14 / 52)$, and cardiopulmonary bypass time more than 60 minutes $(24 \%, 21 / 88)$. The mortality of perioperative myocardial infarcation was 13.6 per cent $(3 / 22)$, while for patients without perioperative myocardial infarction the mortality was 2 per cent $(2 / 101)$. The overall operative mortality was 4 per cent $(5 / 123)$.

The risk of perioperative myocardial infarction is significantly increased by left main coronary artery disease, increased left ventricular end-diastolic pressure, and cardiopulmonary bypass time more than 60 minutes, in patients undergoing coronary artery surgery for unstable angina pectoris. The mortality of perioperative myocardial infarction is high $(13.6 \%)$ in patients with unstable angina.

Surgical treatment for the patient with unstable angina pectoris has become increasingly common as evidenced by mounting reports from many medical centres (Conti et al., 1973; Scanlon et al., 1973; Bertolasi et al., 1974; Bender et al., 1975; Conti et al., 1975; Kouchoukos et al., 1975; Vogel et al., 1975; Berk et al., 1976; Geha et al., 1976). These series have clearly shown that coronary angiography and subsequent aortocoronary bypass grafting in patients with unstable angina pectoris can be performed with an acceptably low mortality rate and can provide substantial relief of symptoms. Coronary bypass surgery is claimed to prevent late myocardial infarction but the incidence of perioperative infarction may be sufficiently great to offset this advantage. It is, therefore, necessary to examine the perioperative myocardial rate in patients treated surgically for unstable angina pectoris.

Received for publication 12 September 1977
In this report, we analyse the incidence, mortality, and factors associated with perioperative myocardial infarction in 123 consecutive patients with unstable angina pectoris who had coronary bypass operations at Yale-New Haven Hospital between January 1974 and June 1975. Data were collected prospectively on each patient and analysed to identify those factors that could predict perioperative myocardial infarction.

\section{Subjects and methods}

From January 1974 to July 1975, the serial electrocardiograms of 123 consecutive patients with unstable angina who had cardiac catheterisation and a coronary artery bypass operation were examined to determine the incidence of perioperative myocardial infarction. The term unstable angina pectoris is used in this study to describe a clinical syndrome characterised by increasing frequency, severity, or both of angina, usually 
requiring emergency admission to hospital, in patients with pre-existing chronic stable angina. The diagnosis was made when all of the following criteria were met: (1) prolonged typical anginal pain (longer than 20 minutes); (2) typical anginal pain occurring at rest or with minimal exertion; (3) pain not completely relieved by glyceryl trinitrate; and (4) failure to document an acute myocardial infarction by serial electrocardiograms and enzyme determinations.

After admission to the hospital, all patients were given maximal medical treatment, including long and short acting nitrates, large doses of propranolol, and complete bed rest.

Cardiac catheterisation was performed at an average of 10 days (range 8 to 18) after admission in patients who responded satisfactorily to medical therapy and were free from pain at rest, though they remained Class III; and at an average of 5 days (range 3 to 10) in patients who continued to have severe angina despite medical treatment. Diagnostic cardiac catheterisation included pressure measurements, cardiac output determination, single plane left ventriculography, and selective coronary arteriography, all performed by standard techniques. Coronary arterial lesions were regarded as significant when the degree of narrowing was more than 70 per cent. Coronary artery disease was recorded as one-, two-, or three-vessel disease. Disease of the proximal left anterior descending artery together with disease of the proximal left circumflex artery was considered equivalent to left main coronary artery disease. The ejection fraction was calculated by the method of Greene et al. (1967) from the right anterior oblique left ventriculogram, which was also used for the assessment of mitral regurgitation.

Coronary artery surgery was performed within 1 week after angiography in the majority of patients and within 2 weeks in all patients. Coronary artery bypass grafting was performed using saphenous veins for the right and left circumflex coronary arteries. The left internal mammary artery was used (in 28 patients) to graft the left anterior descending artery. Dissection of the left internal mammary artery from the chest wall and proximal anastomoses of saphenous vein grafts were both accomplished without cardiopulmonary bypass. Side-biting clamps were used for the proximal anastomosis of the saphenous vein to the aorta. Distal anastomoses were done on full cardiopulmonary bypass with the heart in ventricular fibrillation. Aortic crossclamping was used only when a dry field could not be obtained by local occlusion of the coronary artery. Myocardial revascularisation was considered incomplete if grafts were not placed in each of the significantly diseased coronary branches.

Perioperative myocardial infarction was defined as that occurring within one week of operation, and was identified by serial electrocardiograms. All patients included had standard 12-lead electrocardiograms taken at least daily from admission until the seventh postoperative day. The first postoperative electrocardiogram was taken immediately upon arrival in the surgical intensive care unit. Electrocardiographic criteria of acute myocardial infarction included the acute development of a significant pathological $Q$ wave: the $Q$ wave criteria used were Class I-1 and I-2 of the Minnesota Code (Blackburn et al., 1960). Changes in the ST segment or $T$ waves without new pathological $Q$ waves were not considered as diagnostic of infarction.

For the calculation of mortality, death was attributed to myocardial infarction when it occurred up to 4 weeks after the development of acute myocardial infarction.

Contingency table $\chi^{2}$ (Colton, 1974) was used to analyse the data. This method permitted the examination of each of the study factors in relation to the outcome variable. Factors relating to perioperative myocardial infarction were not necessarily independent influences, but were initially examined one at a time and then in combination. In addition, a multiple logistic regression model (Colton, 1974) was employed to control the simultaneous input of several already known risk factors upon the occurrence of perioperative myocardial infarction. A probability $(P)$ value less than 0.05 was considered statistically significant. When information on a particular preoperative clinical characteristic of a patient was not available, that patient was removed from the analysis of that variable.

\section{Results}

\section{CLINICAL FEATURES}

The average age of the patients was 55 years $\frac{D}{0}$ (range 37 to 76$)$; 96 (78\%) were men; and 27 (22\%) were women. Associated peripheral vascular disease $\sigma$ was present in 18 patients ( $15 \%$ ), diabetes mellitus N in 21 patients $(17 \%)$, lipid abnormalities in 37 N patients (33\%), family history of ischaemic heart $\omega$ disease in 80 patients $(68 \%)$, obesity in 80 patients $(58 \%)$, and hypertension in 37 patients $(30 \%)$. ํำ

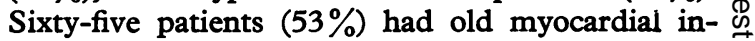
farction; 20 patients $(16 \%)$ had congestive heart 0 failure, and only $14(11 \%)$ had not received $\beta$ adrenergic blocking therapy preoperatively.

Cardiac enlargement (cardiothoracic ratio $>\stackrel{\mathbb{D}}{\circ}$ $50 \%$ ) was present in 24 patients (19\%); normal left ventricular end-diastolic pressure $(\leqslant 12 \mathrm{mmHg})$ 
Table 1 Clinical features of 123 patients with unstable angina pectoris

\begin{tabular}{lll}
\hline & $\begin{array}{l}\text { Number of } \\
\text { patients }\end{array}$ & Per cent \\
\hline Hypertension & $37 / 123$ & 30 \\
Old myocardial infarction & $65 / 122$ & 53 \\
Congestive heart failure & $20 / 123$ & 16 \\
Cardiac enlargement $(\mathrm{CTR} \geqslant 50 \%)$ & $24 / 123$ & 19 \\
Normal LVEDP $(\leqslant 12 \mathrm{~mm} \mathrm{Hg})$ & $71 / 123$ & 58 \\
Normal ejection fraction $(\geqslant 60 \%)$ & $79 / 123$ & 64 \\
Single coronary artery disease & $14 / 123$ & 11 \\
Double coronary artery disease & $32 / 123$ & 26 \\
Triple coronary artery disease & $77 / 123$ & 63 \\
Left main coronary artery disease & $15 / 123$ & 12 \\
\hline
\end{tabular}

was recorded in 71 patients ( $58 \%$ ), normal ejection fraction $(\geqslant 60 \%)$ in 79 patients $(64 \%)$, and mitral regurgitation in 17 patients $(14 \%)$.

Coronary arteriography showed that 14 patients (11\%) had one-vessel disease, 32 patients $(26 \%)$ two-vessel disease, and 77 patients $(63 \%)$ threevessel disease. Left main coronary artery disease was documented in 15 patients ( $12 \%)$. The average number of diseased coronary arteries was (mean \pm standard deviation) $2.5 \pm 0.7$ (Table 1). Twentyone patients $(17 \%)$ had one graft, $42(34 \%)$ had two grafts; $39(31 \%)$ had three grafts; and $21(17 \%)$ had more than three grafts. The average number of grafts performed in each patient was $2.2 \pm 0.7$. Only 55 patients $(45 \%)$ received complete revascularisation.

The duration of the cardiopulmonary bypass was $78 \pm 36$ minutes for the entire group. The mean duration of cardiopulmonary bypass for each graft was 32 minutes. Eighty-eight patients $(72 \%)$ had a cardiopulmonary bypass time more than 60 minutes, and 35 patients $(28 \%)$ had a cardiopulmonary bypass time less than 60 minutes.

\section{INCIDENCE OF PERIOPERATIVE}

MYOCARDIAL INFARCTION

Perioperative myocardial infarction occurred in 18 per cent of patients (22/123). Fifteen infarcts were in the inferior wall, 6 in the anterior wall, and 1 in the anterolateral wall. Twenty patients had electrocardiographic evidence of myocardial infarction on the first postoperative day, but in two patients this did not appear until the third and fourth postoperative days.

No patient sustained an infarction during or after cardiac catheterisation or during the period between catheterisation and operation.

\section{PREDICTION OF PERIOPERATIVE}

MYOCARDIAL INFARCTION

Three factors appeared to be related to the occurrence of perioperative myocardial infarction: left
Table 2 Incidence of perioperative myocardial infarction in 123 patients with unstable angina pectoris

\begin{tabular}{|c|c|c|c|c|c|}
\hline & \multicolumn{2}{|c|}{$\begin{array}{l}\text { Number of } \\
\text { patients }\end{array}$} & \multicolumn{2}{|c|}{$\begin{array}{l}\text { Peripoerative } \\
\text { myocardial } \\
\text { infarction }\end{array}$} & \multirow[t]{2}{*}{$P$} \\
\hline & $\begin{array}{l}\text { With } \\
\text { factor }\end{array}$ & $\begin{array}{l}\text { Without } \\
\text { factor }\end{array}$ & $\begin{array}{l}\text { With } \\
\text { factor }\end{array}$ & $\begin{array}{l}\text { Without } \\
\text { factor }\end{array}$ & \\
\hline \multirow{3}{*}{$\begin{array}{l}\text { Left main coronary } \\
\text { artery disease } \\
\text { Increased LVEDP } \\
(\geqslant 13 \mathrm{~mm} \mathrm{Hg}) \\
\text { Cardiopulmonary } \\
\text { bypass time } \\
\geqslant 60 \mathrm{~min}\end{array}$} & $15 / 123$ & $108 / 123$ & $47 \%$ & $14 \%$ & $<0.05$ \\
\hline & $52 / 123$ & $71 / 123$ & $27 \%$ & $11 \%$ & $<0.03$ \\
\hline & $88 / 123$ & $35 / 123$ & $24 \%$ & $2 \cdot 8 \%$ & $<0.01$ \\
\hline
\end{tabular}

main coronary artery disease, increased left ventricular end-diastolic pressure, and cardiopulmonary bypass time more than 60 minutes. Patients with left main coronary artery disease had more than three times the risk of developing a perioperative myocardial infarction ( $47 \%$ ) than those patients without left main coronary artery disease $(14 \%)$. In patients with left ventricular end-diastolic pressure higher than $13 \mathrm{mmHg}$ the incidence of perioperative infarction was 27 per cent, while in those with normal left ventricular end-diastolic pressure the incidence was only 11 per cent. In patients on cardiopulmonary bypass for 60 minutes or more the risk of infarction $(24 \%)$ was eight times greater than in those who were on cardiopulmonary bypass for less than 60 minutes $(2 \cdot 8 \%$ ) (Table 2). Cardiopulmonary bypass time was prolonged when grafts were anastomosed to coronary vessels with diffuse disease and poor distal run-off on the angiograms.

Perioperative myocardial infarction was not related to age, sex, peripheral vascular disease, diabetes mellitus, lipid abnormalities, family history of ischaemic heart disease, hypertension, history of congestive heart failure, heart size, left ventricular ejection fraction, mitral regurgitation, or number of vessels diseased, except for left main coronary artery disease. The analysis of operative factors indicated that neither the number of grafts nor the completeness of revascularisation had any effect on the incidence of perioperative myocardial infarction. The location of perioperative myocardial infarction was unrelated to the distribution either of a bypassed coronary artery or of a critically stenosed coronary artery which was not bypassed.

To predict more accurately the occurrence of perioperative myocardial infarction in individual patients, combinations of risk factors were examined. The combination of left main coronary artery disease and prolonged cardiopulmonary bypass time ( $\geqslant 60$ minutes) was additive; perioperative myocardial infarction occurred in 50 per cent $(7 / 14)$ of these patients. When both factors were absent, 
Table 3 Perioperative myocardial infarction

\begin{tabular}{|c|c|c|c|c|c|c|c|c|}
\hline \multirow{2}{*}{$\begin{array}{l}\text { Cardiopulmonary } \\
\text { bypass } \\
\text { time }\end{array}$} & \multicolumn{4}{|c|}{ Patients with left main coronary artery disease } & \multicolumn{4}{|c|}{ Patients without left main coronary artery disease } \\
\hline & $\begin{array}{l}\text { Infarction } \\
\text { Number }\end{array}$ & $\%$ & $\begin{array}{l}\text { No infarction } \\
\text { Number } \%\end{array}$ & Total & $\begin{array}{l}\text { Infarction } \\
\text { Number }\end{array}$ & $\%$ & $\begin{array}{l}\text { No infarction } \\
\text { Number } \%\end{array}$ & Total \\
\hline $\begin{array}{l}\geqslant 60 \mathrm{~min} \\
<60 \mathrm{~min} \\
\text { Total }\end{array}$ & $\begin{array}{l}7 \\
0 \\
7\end{array}$ & $\begin{array}{r}50 \\
0\end{array}$ & $\begin{array}{r}50 \\
100\end{array}$ & $\begin{array}{r}14 \\
1 \\
15\end{array}$ & $\begin{array}{r}14 \\
1 \\
15\end{array}$ & $\begin{array}{r}19 \\
3\end{array}$ & $\begin{array}{l}60 \\
33 \\
93\end{array}$ & $\begin{array}{r}74 \\
34 \\
108\end{array}$ \\
\hline
\end{tabular}

perioperative myocardial infarction occurred in only 3 per cent $(1 / 34)(P<0.03)$ (Table 3$)$. Statistical analysis of the interdependence of risk factors showed that left main coronary artery disease and prolonged cardiopulmonary bypass time are independent influences upon perioperative myocardial infarction. Fourteen patients with prolonged cardiopulmonary bypass time ( $\geqslant 60$ minutes) and left main coronary artery disease had an incidence of perioperative myocardial infarction of 50 per cent (7/14), while 74 patients with prolonged cardiopulmonary bypass time ( $\geqslant 60$ minutes) and without left main coronary artery disease had an incidence of perioperative myocardial infarction of only 19 per cent $(14 / 74)(P<0.01)$ (Table 3$)$.

\section{MORTALITY OF PERIOPERATIVE MYOCARDIAL INFARCTION}

The mortality of patients sustaining perioperative myocardial infarction was 13.6 per cent $(3 / 22)$, while for patients without myocardial infarction the mortality was 2.0 per cent $(2 / 101)(P<0.05)$. The overall surgical mortality for the entire group was 4 per cent (5/123). Each of the 3 patients who sustained a perioperative myocardial infarction and died had left main coronary artery disease and had an anterior myocardial infarction.

\section{Discussion}

Patients who were admitted to hospital for unstable angina pectoris were included in this study only if they met rigid diagnostic criteria, and had cardiac catheterisation followed by aortocoronary bypass grafting during the same admission. Therefore, these patients constitute a relatively homogeneous clinical group possessing an especially high risk for myocardial infarction and death (Krauss et al., 1972; Gazes et al., 1973).

Using stringent electrocardiographic criteria, the incidence of perioperative myocardial infarction was 18 per cent $(22 / 123)$ in patients undergoing coronary artery surgery for unstable angina pectoris. This rate is comparable to that reported from several series (Berk et al., 1976; Geha et al., 1976; Righetti et al., 1977) which range from 4 to 27 per cent, the lower rates occurring in studies in which evidence of infarction was not specifically sought. It is likely that the present report underestimates the true incidence of perioperative myocardial infarction, since the rigid electrocardiographic criteria employed probably excluded a significant number of patients with non-transmural myocardial infarction. Similarly, perioperative myocardial infarction might not be detected in individuals with previous electrocardiographic evidence of myocardial infarction. Serial enzyme determinations were not used as serum creatine kinase and aspartate aminotransferase are increased by musculoskeletal operative trauma (Dixon et al., 1972), and a method for estimation of CK iso-enzymes was not available at the time of the study.

\section{PREDICTION OF PERIOPERATIVE}

MYOCARDIAL INFARCTION

Only 3 factors were found to be important in predicting myocardial infarction: left main coronary artery disease, increased left ventricular enddiastolic pressure, and cardiopulmonary bypass time longer than 60 minutes.

The incidence of perioperative myocardial infarction in patients with left main coronary artery disease was 47 per cent (7/15). This figure is significantly higher than that for patients without left main coronary artery disease in whom it was 14.1 per cent $(15 / 108)(P<0.05)$. Zeft et al. (1974) reported an incidence of perioperative myocardial infarction in 56 patients with left main coronary artery disease of only 5 per cent $(2 / 56)$, but did not define their diagnostic criteria. Furthermore, though 42 of their patients $(75 \%)$ were said to have unstable angina their definition was very broad (recent onset, worsening of angina within 6 months, or angina decubitus). It is thus apparent that these authors included a large number of patients with less severe angina than those reported in this series.

Oberman and co-workers (1976) reported an incidence of perioperative myocardial infarction of 6.9 per cent in patients with left main coronary artery disease, 50 per cent of whom appeared to have unstable angina. However, they defined unstable angina as a change in severity of angina during the preceding 3 months. McConahay et al. (1976) 
documented an incidence of perioperative myocardial infarction of 4.8 per cent $(7 / 146)$ in patients with left main coronary artery disease. This report included only 12 patients $(8 \%$ ) with unstable angina as defined in this study, and made no reference to the relation of perioperative myocardial infarction to the clinical characteristics of these patients. The Veterans Administration co-operative randomised study of surgical treatment for patients with significant left main coronary artery lesions (Takaro et al., 1976) did not mention the incidence of perioperative myocardial infarction in the 60 patients treated by aorto-coronary bypass procedures. Several surgical reports (DeMots et al., 1975; Sung et al., 1975; Talano et al., 1975) including large numbers of patients with left main coronary artery disease also fail to mention the incidence of perioperative myocardial infarction.

Increased left ventricular end-diastolic pressure was another preoperative factor influencing the occurrence of perioperative myocardial infarction. In previous studies (Brewer et al., 1973; Espinoza et al., 1974) it has been reported that left ventricular end-diastolic pressure is not a risk factor for perioperative myocardial infarction, though it must be noted that these two studies were concerned with patients with stable angina. The mechanism by which an increased left ventricular end-diastolic pressure might predispose toward perioperative myocardial infarction is not clear. It might reflect, however, the need of these patients for $\beta$-adrenergic blocking agents to control angina.

The third factor that affected mortality was the duration of cardiopulmonary bypass. Several studies in patients with stable angina pectoris (Dixon et al., 1972; Rose et al., 1974; AssadMorrell et al., 1975) have found a correlation between bypass time and the incidence of perioperative myocardial infarction. Our study suggests that cardiopulmonary bypass time also affects the perioperative myocardial infarction rate in patients with unstable angina. Cardiopulmonary bypass time more than 60 minutes was usually associated with technically difficult anastomoses between the grafts and diffusely diseased coronary arteries. Bulkley and Hutchins (1977) recently reported on the pathological findings in patients dying after coronary bypass operations. Their observations suggested that inadequate myocardial support procedures during operation, rather than graft or intrinsic coronary artery occlusion, accounted for the majority of perioperative myocardial infarctions. These results appear to be supported by our clinical study: first, no relation was found between the location of perioperative myocardial infarction and the distribution of revascularisation; and second, the crucial role found for cardiopulmonary bypass duration in the development of perioperative myocardial infarction.

The statistical analysis of the interdependence of risk factors has been included in the results section because factors relating to perioperative myocardial infarction are not necessarily independent influences. This analysis has shown: (1) that the combination of left main coronary artery disease and prolonged cardiopulmonary bypass time ( $\geqslant 60$ minutes) identifies most clearly the high risk patient for coronary surgery (Table 3); (2) that left main coronary artery disease and prolonged cardiopulmonary bypass time ( $\geqslant 60$ minutes) are independent risk factors (Table 3).

The mortality of perioperative myocardial infarction in this study was 13.6 per cent $(3 / 22)$, while the mortality in patients who had no infarction was 2 per cent $(2 / 101)$. This high mortality rate is similar to that reported in other recent studies (Anderson et al., 1974; Najmi et al., 1974; Assad-Morrell et al., 1975) which range from 15 to 41 per cent. Thus, it appears that perioperative myocardial infarction is not a benign event.

There were no myocardial infarctions or deaths related to cardiac catheterisation in this study, even though the risk of diagnostic cardiac catheterisation in patients with unstable angina is higher than in patients with stable angina pectoris. The 53 patients who responded satisfactorily to medical treatment had cardiac catheterisation between 8 to 18 days (mean 10 days) after admission, while the 70 patients who did not respond to medical treatment had cardiac catheterisation between 3 to 10 days (mean 5 days) after admission. In the latter group, 26 patients required the insertion of an intra-aortic balloon pump to stabilise their symptoms before cardiac catheterisation and operation. Coronary artery revascularisation was performed in the great majority of patients within 1 week of cardiac catheterisation and in all patients within 2 weeks.

We suggest that the treatment given to these patients may have minimised the risk of myocardial infarction or death at or after cardiac catheterisation and conclude that early study and early surgical intervention is feasible for patients with unstable angina. The therapeutic goal is the relief of angina pectoris. The risk of perioperative myocardial infarction is high $(18 \%)$ and is significantly increased by the presence of left main coronary artery disease, an increased left ventricular end-diastolic pressure, and cardiopulmonary bypass time more than 60 minutes. Whether the infarction rate would be lower or higher if patients were treated medically rather 
than surgically has not been answered by this investigation.

\section{References}

Anderson, R. P., Rahimtoola, S. H., Bonchek, L. I., and Starr, A. (1974). The prognosis of patients with coronary artery disease after coronary bypass operations: timerelated progress of 532 patients with disabling angina pectoris. Circulation, 50, 274-282.

Assad-Morrell, J. L., Frye, R. L., Connolly, C. D., Gau, G. T., Pluth, J. R., Barnhorst, D. A., Wallace, R. B., Davis, G. D., Elveback, L. R., and Danielson, G. K. (1975). Relation of intraoperative or early postoperative transmural myocardial infarction to patency of aortocoronary bypass grafts and to diseased ungrafted coronary arteries. American fournal of Cardiology, 35, 767-773.

Bender, H., Jr., Fisher, D., Faulkner, S., and Friesinger, G. C. (1975). Unstable coronary disease: comparison of medical and surgical treatment. Annals of Thoracic Surgery, 19, 521-528.

Berk, G., Kaplitt, M., Padmanabhan, V., Frantz, S., Morrison, J., and Gulotta, S. J. (1976). Management of preinfarction angina: evaluation and comparison of medical versus surgical therapy in 43 patients. Fournal of Thoracic and Cardiovascular Surgery, 71, 110-117.

Bertolasi, C. A., Trongé, J. E., Carreño, C. A., Jalon, J., and Vega, M. R. (1974). Unstable angina: prospective and randomized study of its evaluation with and without surgery. American fournal of Cardiology, 33, 201-208.

Blackburn, H., Keys, A., Simonson, E., Rautharju, P., and Punsar, S. (1960). The electrocardiogram in population studies: a classification system. Circulation, 21, 1160-1175.

Brewer, D. L., Bilbro, R. H., and Bartel, A. G. (1973). Myocardial infarction as a complication of coronary bypass surgery. Circulation, 47, 58-64.

Bulkley, B. H., and Hutchins, G. M. (1977). Myocardial consequences of coronary artery bypass graft surgery: a clinicopathological study of 53 patients (abstract). American fournal of Cardiology, 39, 268.

Colton, T. (1974). Statistics in Medicine, p. 284. Little, Brown, Boston.

Conti, C., Brawley, R., Griffith, L., Pitt, B., Humphries, J. O., Gott, V. L., and Ross, R. S. (1973). Unstable angina pectoris: morbidity and mortality in 57 consecutive patients evaluated angiographically. American fournal of Cardiology, 32, 745-750.

Conti, C., Gilbert, J., Hodges, M., Hutter, A. M., Jr., Kaplan, E. M., Newell, J. B., Resnekov, L., Rosati, R. A., Ross, R. S., Russell, R. O., Schroeder, J. S., and Wolk, M. (1975). Unstable angina pectoris: randomized study of surgical vs medical therapy (abstract). American fournal of Cardiology, 35, 129.

DeMots, H., Bonchek, L., Rösch, J., Anderson, R. P., Starr, A., and Rahimtoola, S. H. (1975). Left main coronary artery disease. Risk of angiography, importance of coexisting disease of other coronary arteries and effects of revascularization. American fournal of Cardiology, 36, 136-141.

Dixon, S. H., Limbird, L. E., Roe, C. R., Wagner, G. S., Oldham, H. N., and Sabiston, D. O. (1972). Recognition of postoperative myocardial infarction (abstract). Circulation, 45 and 46, Suppl. II, 79.

Espinoza, J., Lipski, J., Litwak, R., Donoso, E., and Dack, S. (1974). New $Q$ waves after coronary artery bypass surgery for angina pectoris. American fournal of Cardiology, 33, 221-224.

Gazes, P. C., Mobley, E. M., Faris, H. M., Duncan, R. C., and Humphries, G. B. (1973). Preinfarction (unstable) angina-a prospective study-ten year follow-up. Circulation, 48, 331-337.
Geha, A. S., Baue, A. E., Krone, R. J., Kleiger, R. E., Oliver, J. C., McCormick, J. R., and Salami, A. (1976). Surgical treatment of unstable angina by saphenous vein and internal mammary artery bypass grafting. Fournal of Thoracic and Cardiovascular Surgery, 71, 348-354.

Greene, D. G., Carlisle, R., Grant, G., and Bunnel, I. L. (1967). Estimation of left ventricular volume by one-plane cineagiography. Circulation, 35, 61-69.

Kouchoukos, N., Russell, R., Jr., Moraski, R., Karp, R. B., Oberman, A., and Rackley, C. E. (1975). Surgical treatment of unstable angina pectoris; results in 65 patients (abstract). American fournal of Cardiology, 35, 149.

Krauss, K. R., Hutter, A. M., Jr., and DeSanctis, R. W. (1972). Acute coronary insufficiency: course and follow-up. Archives of Internal Medicine, 129, 808-813.

McConahay, D. R., Killen, D. A., McCallister, M. A., Arnold, M., Reed, W. A., Crockett, J. E., and Bell, H. H. (1976). Coronary artery bypass surgery for left main coronary artery disease. American fournal of Cardiology, 37, 885-889.

Najmi, M., Ushiyama, K., Blanco, G., Adams, A., and Segal, B. L. (1974). Results of aortocoronary artery saphenous vein bypass surgery for ischemic heart disease. American Fournal of Cardiology, 33, 42-48.

Oberman, A., Harrell, R. R., Russell, R. O., Jr., Kouchoukos, N. T., Holt, J. H., Jr., and Rackley, C. E. (1976). Surgical versus medical treatment in disease of the left main coronary artery. Lancet, 2, 591-594.

Righetti, A., Crawford, M. H., O'Rourke, R. H., Hardarson, T., Schelbert, H., Daily, P. O., DeLuca, M., Ashburn, W., and Ross, J., Jr. (1977). Detection of perioperative myocardial damage after coronary artery bypass graft surgery. Circulation, 55, 173-178.

Rose, R., Glassman, E., Isom, O. W., and Spencer, F. C. (1974). Electrocardiographic and serum enzyme changes of myocardial infarction after coronary artery bypass surgery. American fournal of Cardiology, 33, 215-220.

Scanlon, P., Nemickas, R., Moran, J. F., Talano, J. V., Amirparviz, F., and Pifarre, R. (1973). Accelerated angina pectoris: clinical, hemodynamic, arteriographic and therapeutic experience in 85 patients. Circulation, 47, 19-26.

Sung, R. J., Mallon, S. M., Richter, S. E., Gahramani, A. E., Sommer, L. S., Kaiser, G. A., and Myerburg, R. J. (1975). Left main coronary artery obstruction: follow-up of thirty patients with and without surgery. Circulation, 51 and 52, Suppl. I, 112-118.

Takaro, T., Hultgren, H. N., Lipton, M. J., Detre, K. M., and participants in the study group (1976). The V. A. cooperative randomized study of surgery for coronary arterial occlusive disease. II. Subgroup with significant left main lesions. Circulation, 54, 107-117.

Talano, J. V., Scanlon, P. J., Meadows, W. R., Kahn, M., Pifarre, R., and Gunnar, R. M. (1975). Influence of surgery on survival in 145 patients with left main coronary artery disease. Circulation, 51 and 52, Suppl. I, 105-111.

Vogel, R., Pappas, G., Levitt, P., Battock, D., and Steele, P. (1975). Results of medical and surgical management of high-risk unstable angina (abstract). American fournal of Cardiology, 35, 175.

Zeft, H. J., Manley, J. C., Huston, J. H., Tector, A. J., Auer, J. E., and Johnson, W. D. (1974). Left main coronary stenosis: results of coronary bypass surgery. Circulation, 49, 68-76.

Requests for reprints to Dr Rene A. Langou, Cardiology Section, Yale University School of Medicine, 333 Cedar Street, 87 LMP, New Haven, Connecticut 06510, USA.

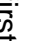
. 앙 ชั

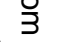

